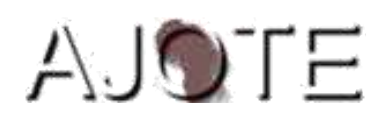

African Journal of Teacher Education

ISSN 1916-7822. A Journal of Spread Corporation

Volume 10. No. 12021 Pages 1-20

\title{
Status of Zambia's Inclusive Education through the Lenses of Teachers
}

\author{
Kenneth Kapalu Muzata ${ }^{1}$, Francis Simui ${ }^{1}$, \\ Dikeledi Mahlo ${ }^{2}$ \& Phydes Ng'uni ${ }^{1}$ \\ ${ }^{1}$ University of Zambia, Department of Educational Psychology, \\ Sociology and Special Education \\ ${ }^{2}$ Department for Inclusive Education, University of South Africa (UNISA)
}

\begin{abstract}
This study was conducted to examine the status of inclusive education in Zambia, learning from teachers' perspectives about how inclusive education is being implemented and the whether teachers receive adequate support to implement inclusive education to learners with disabilities. The study employed a concurrent mixed design approach in which both quantitative and qualitative data were generated and applied. Open and closed ended questionnaires were used to collect data from teachers that were upgrading their qualifications via distance education at Kwame Nkrumah University, University of Zambia and Chalimbana University. Findings indicated that Zambia practices partial inclusion in which only the mild and moderate learners with disabilities are included in classrooms. Inclusive education is understood by teachers in the context of disability and teachers reported that they did not receive adequate support to implement inclusive education effectively. It is recommended that the Government of the Republic of Zambia through the Ministry of General Education should focus on training teachers in inclusive education and its methodologies to meet the learning needs of learners from different circumstances.
\end{abstract}

\section{Context}

Zambia's education system is anchored on the principle of a democratic society (Ministry of Education, 1996), which is actually the overall purpose of inclusion. The inclusive education philosophy is basically a democratic philosophy seeking to have everybody involved in national affairs. Zambia has made serious commitments to the education of persons with disabilities by assenting to the various conventions on education and rights of persons with 
disabilities. The country participated in the Salamanca conference in 1994 which endorsed nondiscriminatory education systems and also assented to the Convention on the rights of the child (United nations, 1989). Zambia made a commitment to embrace the Sustainable Development Goal number 4 which emphaises inclusive, equity and lifelong learning skills for all, including persons with disabilities. Such commitments should translate into practical provision of services for persons with disability and specifically affirm their right to education. The Mission of the Ministry of Education- Zambia in the 1996 Educating our Future policy document says;

The mission of the Ministry of Education is to guide the provision of education for all Zambians so that they are able to pursue knowledge and skills, manifest excellence in performance and moral uprightness, defend democratic ideals, and accept and value other persons on the basis of their personal worth and dignity, irrespective of gender, religion, ethnic origin, or any other discriminatory characteristic (MoE 1996: xi)

Zambia has made steady progress in the provision of inclusive education, starting with pilot programmes between 1997 and 2001 in Kalulushi, North Western and Western Provinces of the country (Ndonyo, 2007). It is commendable that the country has devised policies and legislation on the education of persons with disabilities and inclusive education in particular (Chitiyo \& Muwana, 2018; GRZ, 2012; MESVETEE, 2013; MoGE, 2016; MoE, 1996). Mumba (2000), a Zambian teacher in Mpika affirms that inclusion is workable when classroom pedagogies are democratised, submitting that the use of twinning learners, home visits, and use of democratic methods are effective strategies for making inclusion workable. Nonetheless, several studies have highlighted several challenges in the implementation of inclusive education in Zambia. For instance, while Muwana, (2012) reports positive attitudes in University of Zambia students towards inclusion other studies record that negative attitudes towards disability by teachers, learners and the surrounding community still exist especially in schools (Simui, Kasonde-Ngandu, Cheyeka \& Makoe, 2019; Banja \& Mandyata, 2018; Ministry of Community Development NDS report 2018; Muzata, Simalalo, Kasonde-Ng'andu, Mahlo, Banja, \& Mtonga, 2019). Simui (2018) reported that students with visual impairments did not feel the positive impact of their inclusion at SIM University (Pseudonym) because there were negative attitudes by lecturers, problems of inaccessible environments and inaccessible learning materials, exclusive assessment system used by lecturers, exclusive pedagogy and limited orientation and mobility difficulties which acted as barriers to their inclusion. 
Lack of skills for teaching learners with disabilities in Zambian schools has been a topical issue over the years. Many studies and education documents report teachers' lack of sign language and braille skills as well as lack of knowledge to adapt the curriculum to suit the needs of learners with special education needs (Mulonda, 2013; Muzata, 2018; Muzata \& Mahlo, 2019, Simui, 2018, Kasongole \& Muzata, 2020, MoE, 2014) among others.

Concerns about unfriendly structures as a barrier to access for learners with disabilities, lack of funding of inclusive education and lack of materials suitable for learners with disabilities have been documented in the literature, all the challenges that affect the implementation of inclusive education in the country. However, this study raises the question of what has changed since the introduction in the late 1990s and early 2000s of inclusive education in Zambia. The study therefore examines the status of inclusive education in Zambia, using the perspectives of teachers who are the implementers of the curriculum in schools.

\section{Statement of a Problem}

Strides have been made to provide inclusive education in Zambia as noted through the Ministry of Education policies and the disability act of 2012. While a legal framework and policies supporting the implementation of inclusive education exist, there has been no dedicated study to examine the status of inclusive education practice from the teacher perspective in Zambia. This study was conducted to examine the status of inclusive education in Zambia from teachers' perspectives since they are the implementers of the curriculum in the classroom.

\section{Research Questions}

The study was guided by three main research questions;

i. What is the nature of inclusion practiced in Zambian schools?

ii. Is inclusive education working out well for children with disabilities?

iii. What are teachers' perceptions towards Government support for Inclusive education?

\section{Theoretical Foundation of the Study}

This study is pinned to the Social Model of Disability which posts that persons with disability are more disabled by the society than the disabilities and impairments they have. Thus, society has been coined to possess unbearable barriers that disable persons with disability participation in the activities of their own communities and livelihood. If humans were regarded as equal, there would be no barriers to create unequal competition. Most importantly, the web of challenges that persons with disability face is shrouded around negative attitudes. The 
argument within the social model is that society disables people and makes them incapacitated by excluding them from full participation in society thereby making persons with disability an oppressed lot (Anastasio \& Kauffman, 2013, Retief \& Letšosa, (2018). For this study, while Anastasio \& Kauffman, (2013) caution the social model against ignoring the influence of heredity, we argue that heredity aside, with support based on equality, the argument by the social model still persists that there is more exclusion by society than by the disability itself which worsens the influence that heredity poses. The barriers in society have denied more persons with disability opportunities to education due to stigma and the feeling that persons with disabilities are unable yet in many cases, they can especially with support. Thus, society has a major influence to change one's hereditary potential and become an effective member of a society.

\section{Methodology}

The study employed a concurrent mixed design approach in which both quantitative and qualitative data were applied. Open and closed ended questionnaires were used to generate data from $104(29 ; 27.9 \%$ males and $(75 ; 72.1 \%)$ female teachers that were upgrading their qualifications via distance education at Kwame Nkrumah University, University of Zambia and Chalimbana University. The researchers engaged participants during school sessions at the three universities in 2019. Participants were drawn from Zambia's 10 provinces as follows; Lusaka $(15 ; 14.4 \%)$, Central $(13 ; 12.5 \%)$, Copperbelt $(19 ; 18.3 \%)$, Eastern $(12 ; 11.5 \%)$, Southern $(8 ; 7.7 \%)$ and Northern provinces $(2 ; 1.9 \%)$. Other provinces were North Western $(16 ; 15.4 \%)$, Western $(5 ; 4.8 \%)$, Luapula $(3 ; 2.9 \%)$ and Muchinga $(10 ; 9.6 \%)$. There was a missing system number of $(1 ; 1 \%)$. The sampling by convenience meant that there was uneven representation of participants from all the provinces which thereby indicates a limitation in the generalisation of the data by province, although the data is generalizable by its collection of participants within the same profession.

The demographics further show that 30 (28.8\%) of the participants were specialised in special education, 25 (24\%) received capacity building in inclusive education, while 45 $(43.3 \%)$ were general teachers but equally taught in inclusive classrooms. From the total 104, $(4 ; 3.8 \%)$ did not provide their demographic information. All the participants had teaching experience ranging from 5 to over 20 years with $(45,43.3 \%)$, having certificate in primary teaching, $(37,35.6 \%)$, diploma and $(18,17.3 \%)$, with graduate degrees in teaching. Four of the participants $(4 ; 3.8 \%)$ had other qualifications. Most participants, $(87 ; 83.7 \%)$, were from government schools while $(7 ; 6.7 \%)$ were from private schools, $(3 ; 2.9 \%)$, were community 
teachers and four $(4 ; 3.8 \%)$ were from religious schools. From the demographic data, we concluded the participants were a satisfactory population for the study.

\section{Description of the Instrument}

We used a questionnaire with both open and closed ended questions to generate both qualitative and quantitative data. The questionnaire had three sections; first section collected personal data about the participants in order to obtain their characteristics to validate their participation in the study, the second section collected information on whether teachers' classrooms had learners with disabilities included in them, what types of disabilities were included, their understanding of the concept of inclusive education, whether they thought inclusion was working well in their schools, and what reasons could be facilitating or disabling the effective implementation of inclusive education in their respective schools. The section also had questions that sought to elicit responses on how teachers perceived Government support to inclusive education in Zambia and possible reasons for their answers.

\section{Analysis}

Data was analysed by employing both quantitative and qualitative methods. Quantitative data was coded in the Statistical Package for Social Sciences (SPSS- Version 16). We were able to derive statistics in form of frequencies and percentages. Some comparisons were made on variables such as sex and levels of qualifications, province and experience to see whether there were significant differences in the understanding of inclusive education or not, thereby certifying the reliability and validity of the data that was collected. Qualitative data was analysed thematically to provide the reasons for the implementation of inclusive education in Zambia. The qualitative data were analysed thematically using Nvivo Pro Version 10 to code for density and to run word queries.

\section{Study Findings}

Some themes that emerged from the findings derived primarily from the research questions such as nature of inclusive education practices, Effectiveness of inclusive education among children with disabilities and Teachers' perceptions towards Government support for Inclusive education.

\section{Nature of Inclusive Education Practices}

Teachers were asked whether the classes they taught were inclusive or not. The results showed that $62(59.6 \%)$ of the teachers' classrooms are inclusive while $32(30.8 \%)$ are not. Teachers 
reported that their classrooms included learners with disabilities such as visual impairments, hearing impairments, physical disability, learning disability and speech disorder. However, some classes had a combination of students with different disabilities learning together with those without disabilities while other classes did not have any learners with disabilities. Figure 1 shows the categories of disabilities in Zambia's inclusive classrooms:

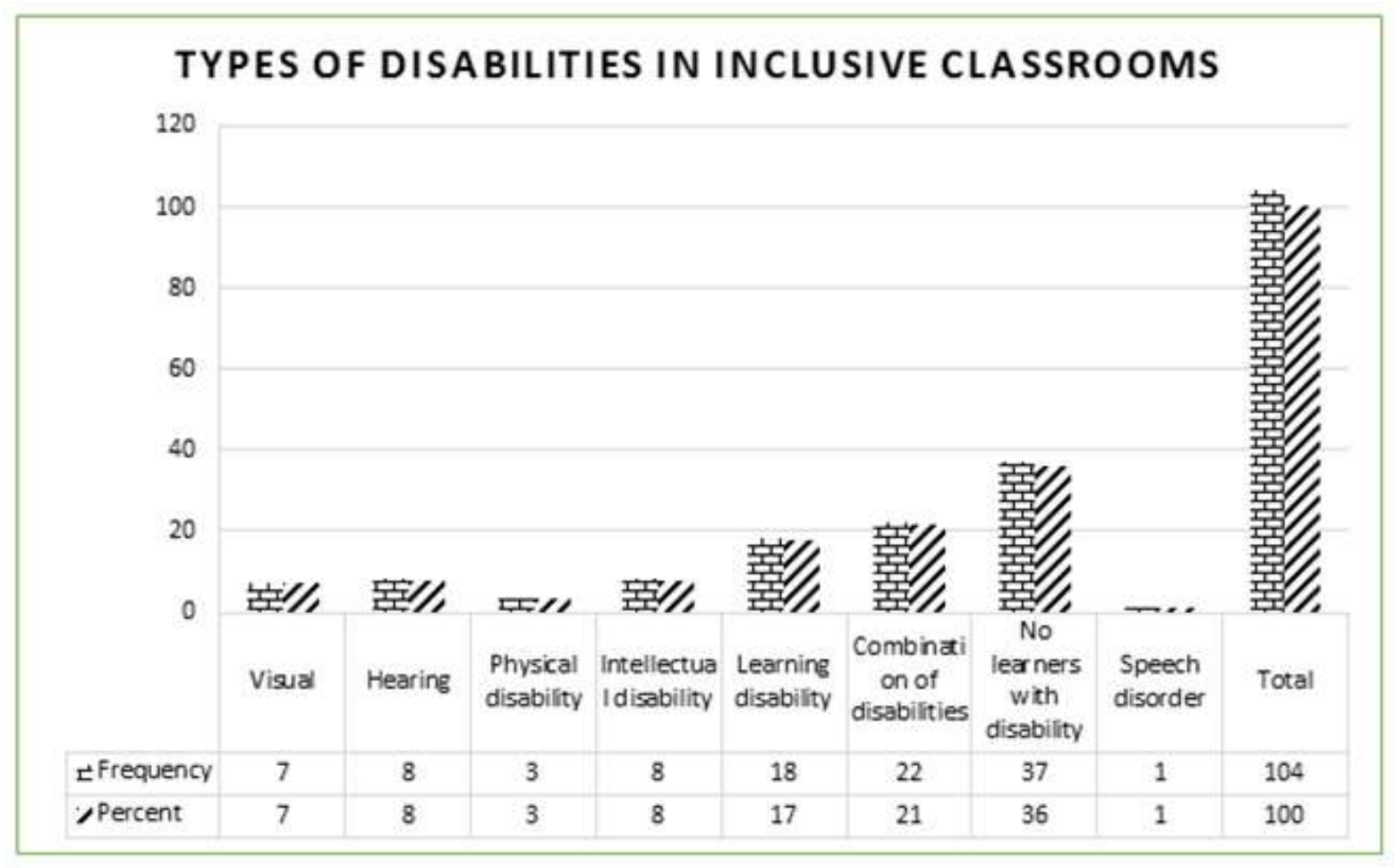

Figure 1: Results showing types of disabilities in inclusive classrooms. Source: Field data.

The results therefore demonstrate that there are learners with disabilities in inclusive classrooms in Zambia. Learners with disabilities are the most commonly included. However, the degree of disabilities included in Zambian classrooms is mostly learners with mild and moderate disabilities. The figure 2 shows the results; 


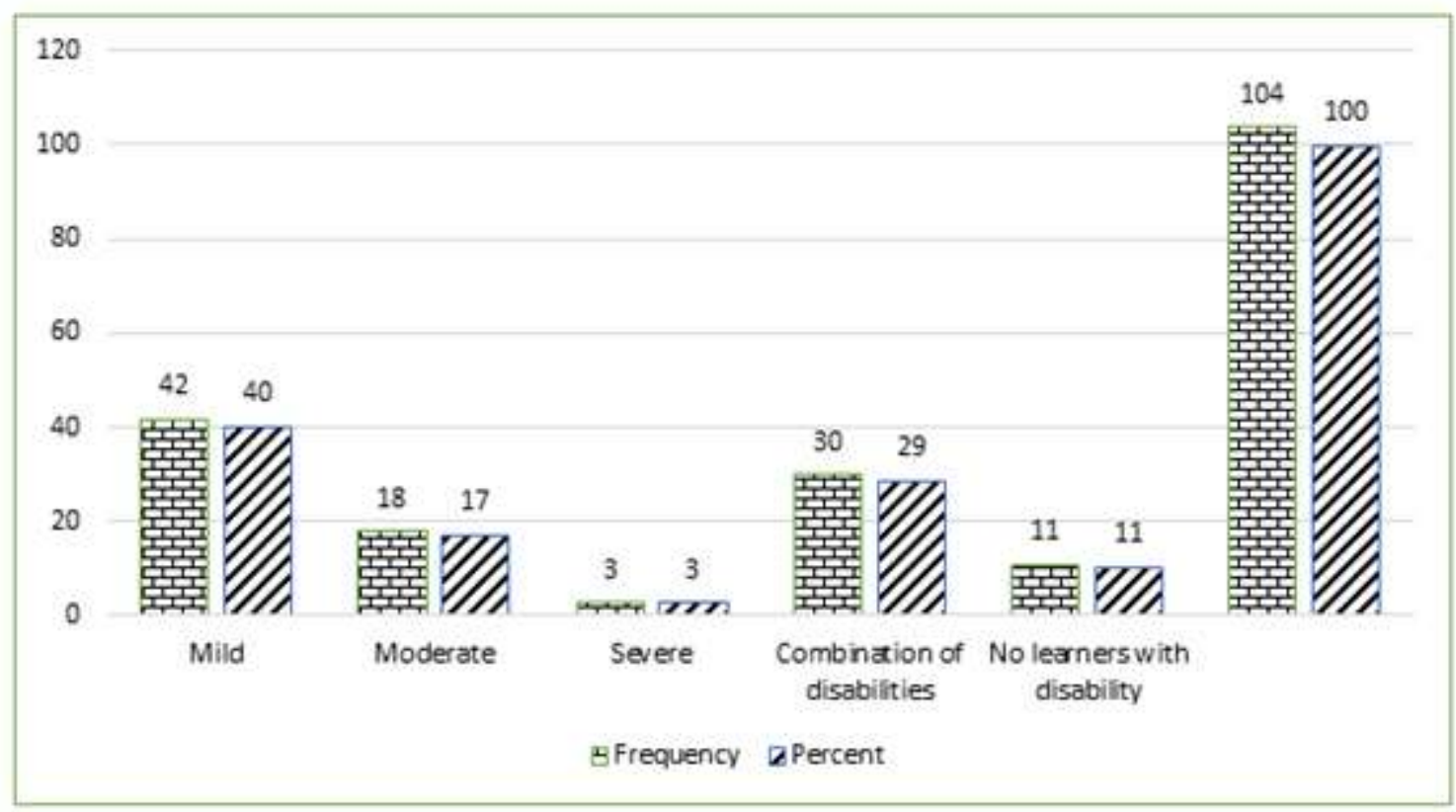

Figure 2: Degree of disability in inclusive classrooms. Source: Field data.

From the results, it appears that participants' construed inclusion in terms of disability because none of the teachers wrote any other vulnerable learners as being included in their classrooms. Thus, the construction of inclusive education is associated with learners with disabilities learning together with those without disabilities in the same classroom. With this in mind, we asked participants to give their opinions about what inclusive education is. The coding density from NVIVO showed that teachers understood inclusion in terms of placing learners with disabilities within the mainstream classroom to learn together with those without disabilities. The following were sampled definitions,

This is the type of education where learners with disabilities learn together with learners without disabilities and use the same educational resources and curriculum. (Teacher 1, Female- Northern Province)

Inclusive education refers to the model wherein special needs children spend most of their time learning with non- special needs children. (Teacher 14, FemaleLusaka Province)

Mixing the disabled learners with the so called normal ones (Teacher 103, Female- Copperbelt Province) 
This is where learners with disabilities learn together with learners without disabilities from the same teacher, using the same curriculum, teaching and learning materials, teaching and learning methods, study the same subjects, take the same examinations and obtain the same educational qualifications. (Teacher 3, Male- Copperbelt Province)

From the qualitative perspective, Text Query Analysis in Nvivo showed the word disability emerging prominent with 86 appearances while other words used in defining inclusive education were special education needs, normal, abnormal children, impaired and handicapped children. The definitions demonstrate teachers understanding of inclusive education as inclined to disability.

Teachers' Perspectives of Whether Inclusive Education is Benefiting Children with Disabilities.

Table 1: Responses about whether inclusive education is working well for children with disabilities

\begin{tabular}{|c|c|c|c|c|}
\hline Category & Province & Yes & No & Total \\
\hline \multirow[t]{10}{*}{$\begin{array}{l}\text { 1. Is inclusive education working } \\
\text { well? }\end{array}$} & Lusaka & 7 & 8 & 15 \\
\hline & Central & 5 & 6 & 11 \\
\hline & Copperbelt & 8 & 10 & 18 \\
\hline & Eastern & 6 & 6 & 12 \\
\hline & Southern & 4 & 4 & 8 \\
\hline & Northern & 1 & 1 & 2 \\
\hline & $\begin{array}{l}\text { North } \\
\text { western }\end{array}$ & 7 & 7 & 14 \\
\hline & Western & 2 & 3 & 5 \\
\hline & Luapula & 1 & 2 & 3 \\
\hline & Muchinga & 5 & 5 & 10 \\
\hline Total & & 46 & 52 & 98 \\
\hline
\end{tabular}




\begin{tabular}{|l|l|l|l|l|}
\hline $\begin{array}{l}\text { 2. Is Government policy on IE } \\
\text { being followed? }\end{array}$ & Lusaka & 10 & 5 & 15 \\
\hline \multirow{2}{*}{ Central } & 8 & 4 & 12 \\
\cline { 2 - 6 } & Copperbelt & 11 & 5 & 16 \\
\cline { 2 - 6 } & Eastern & 7 & 4 & 11 \\
\cline { 2 - 6 } & Southern & 5 & 3 & 8 \\
\cline { 2 - 6 } & Northern & 1 & 1 & 2 \\
\hline & North & & & \\
\hline & western & 11 & 5 & 16 \\
\hline & Western & 3 & 2 & 5 \\
\hline & Luapula & 1 & 1 & 2 \\
\hline & Muchinga & 6 & 3 & 9 \\
\hline & Total & $\mathbf{6 4}$ & $\mathbf{3 2}$ & $\mathbf{9 6}$ \\
\hline
\end{tabular}

The responses imply that though the schools seem to adhere to government policy on inclusion, inclusive education in itself is not working well in the schools. There were no significant differences in the responses after the data was subjected to Chi-square computation, showing $\left(\chi^{2}(9, n=98)=5.02, p>.83\right)$ for category 1 and $\left(\chi^{2}(9, n=96)=8.94, p>.44\right)$ for category 2 . The results therefore rule out any possible hypothesis that inclusive education maybe well implemented in one province than another. Qualitative data corroborated the findings on the reasons inclusive education was viewed as not working well for children with disabilities in Zambia:

Some children especially those with severe disabilities do not benefit for their educational needs are not fully met in these inclusive setups due to various reasons such as teacher attitudes and school environmental factors (Teacher 1, FemaleNorthern Province).

Teachers have no knowledge of handling pupils with learning disabilities (Teacher 8, Male- Eastern Province). 
It does not work well in the sense that some disabilities are not noticeable and hence there is no care for such children (Teacher 38, Female; Muchinga Province).

It's not easy because other learners have severe disabilities and much time is spent on those children than the others (Teacher 13, Female; Lusaka).

Because most of the teachers have not acquired relevant skills for handling learners with disabilities and usually disabled learners are labelled. (Teacher 25, Female; Western Province)

The excerpt from Teacher 38 is one of the insightful responses that points to the negation of screening and assessment of disabilities where children with disabilities maybe many in inclusive classrooms but are not easily identified in ways that allow them to be provided with the necessary inclusive teaching and learning strategies. The spider-gram in figure 4 below shows a summary of participants' explanations for why inclusive education fails to work well.

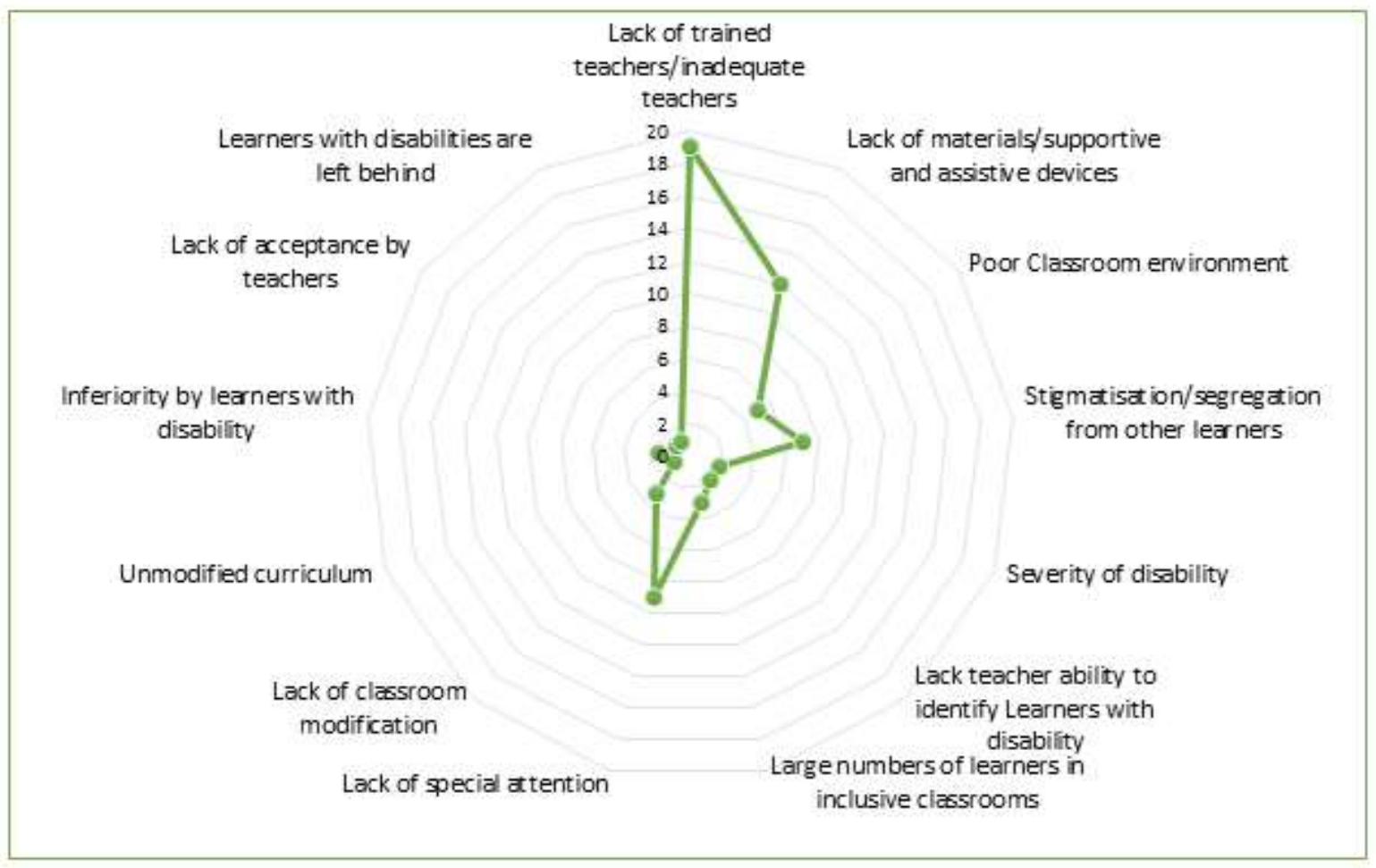

Figure 3: Why Inclusive education is not working well

According to teachers, lack of trained teachers/inadequate teachers was the greatest challenge hindering the successful implementation of inclusive education in Zambia. This was followed by lack of supportive assistive devices, lack of special attention, and stigmatisation from other 
learners. Other factors accounting for limited uptake of inclusive education include: (i) poor classroom environment, (ii) severity of disability, (iii) teacher lack of ability to identify learners with disability, (iv) large numbers of learners in inclusive classrooms and (v) non-modification of classroom setting. Other reasons provided for why inclusive education is not working well in Zambia included unmodified curriculum, feelings of inferiority by learners with disability, lack of acceptance by teachers, and failure to bring learners with disabilities along in class implementation of curriculum.

Teachers who said it was working supported the idea of inclusive education from a sympathetic point of view. For instance, one of the teachers said

It is cheaper for the disabled children to learn with normal children because normal children help those with disabilities. (Teacher 56, Female; Central province)

It is helping learners with disabilities to be accepted by fellow learners without disabilities, it is also helping them in academic and social life. (Teacher 59, Male; Western Province)

Other reasons given by those who hold this positive view of the state of inclusive education in Zambia are that their inclusion in mixed classrooms helps to improve the self-esteem of learners with disabilities and facilitates the reduction or elimination of inferiority complex. They also reported that the learners with disabilities in their mixed classroom settings feel a sense of belonging with the broader group of learners without disabilities.

\section{Teachers' Perceptions of Government Support for Inclusive Education.}

When teachers were asked whether they thought government was supporting inclusive education in Zambia. The table below shows results of a cross tabulation to see how different provinces compared in terms of responses:

Table 3: Teachers' opinions on whether Government was supporting Inclusive Education

\begin{tabular}{|l|l|l|l|l|l|l|l|}
\hline Category & Province & Yes & Percent & No & Percent & Total & Percent \\
\hline $\begin{array}{l}\text { Is there enough support for IE by } \\
\text { GOVT }\end{array}$ & Lusaka & 5 & 5 & 10 & 5 & 15 & 15 \\
\hline & Central & 4 & 4 & 8 & 4 & 12 & 12 \\
\cline { 2 - 9 }
\end{tabular}




\begin{tabular}{|c|c|c|c|c|c|c|c|}
\hline & Copperbelt & 7 & 7 & 10 & 7 & 17 & 18 \\
\hline & Eastern & 5 & 5 & 6 & 5 & 11 & 11 \\
\hline & Southern & 1 & 1 & 7 & 1 & 8 & 8 \\
\hline & Northern & 0 & 0 & 2 & 0 & 2 & 2 \\
\hline & $\begin{array}{l}\text { North } \\
\text { western }\end{array}$ & 2 & 2 & 14 & 2 & 16 & 16 \\
\hline & Western & 1 & 1 & 4 & 1 & 5 & 5 \\
\hline & Luapula & 1 & 1 & 1 & 1 & 2 & 2 \\
\hline & Muchinga & 3 & 3 & 6 & 3 & 9 & 9 \\
\hline Total & & 29 & 30 & 68 & 31 & 97 & 100 \\
\hline
\end{tabular}

From the results, teachers believe that the Government of Zambia was not doing enough to support inclusive education in the country. Responses from all provinces showed no significant differences at $\left(\chi^{2}(9, \mathrm{n}=97)=7.44, \mathrm{p}>.591\right)$ Chi-square calculation. When they were asked to give reasons for the responses they provided, answers were that,

Government is not providing support because there is no follow up in schools to make sure that the school respects this policy as well as train teachers to handle such children or teaching these children (Teacher 104, Female; Copperbelt Province)

The children with special needs are just accepted in school but they have no proper resources to support their learning (Teacher 99, Female; North Western Province).

The government has focussed so much on implementing inclusive education in urban areas making rural areas to be disadvantaged due to lack of infrastructure and materials to support inclusive education (Teacher 73, Female; Central Province).

This failure is attributed to lack of resources and failure to adequately plan for the marginalised in society (Teacher 74, Male; Central Province).

There isn't infrastructure to support these learners with disabilities and materials as well (Teacher 80, Female; Luapula Province). 
The results point to many factors affecting the implementation of inclusive education in Zambian schools. Insufficient teacher training, lack of specialised materials, lack of teacher skills and monitoring as well as lack of planning for learners with special needs in inclusive schools are among the many factors teachers mentioned.

However, a few teachers also thought inclusive education was being well supported by government. Two teachers in the Eastern Province asserted,

Most of the new schools being built have facilities that support the learning of disabled pupils (Teacher 75, Female; Eastern Province).

Because government has allowed all learners to learn together in the same environment regardless of the status (Teacher 89, Female; Eastern Province)

Teacher 92, Female from North Western also shared the same view with (Teacher 75, Female; Eastern Province) while two others shared the second view by teacher 89 .

\section{Discussion of Findings}

This study has revealed the current state of inclusive education in Zambia. We learn that inclusive education is being practiced in schools and only learners with mild and moderate disabilities are included in mainstream classroom, while those with severe disabilities remain in special schools and units. The results reveal an adherence to the Ministry of General Education policy of inclusion (Ministry of Education, 1996; 2016, Ministry of Community Development, 2018). The current mode of implementation of inclusive education which supports learners with mild and moderate disabilities only does not equate to full inclusion. Inclusive education is not a selective practice where some learners are included while others are not because every child has the right to learn from the school in the community where he or she belongs. Based on their definitions, the teachers' construction of inclusive education is associated with disability (Mugambi, 2017), in accordance with studies in Finland by Paju, Kajamaa, Pirttimaa \& Kontu, 2018. We would not blame the teachers for their narrow understanding of the concept because the history of inclusive education has to do with the fight for the rights of persons with disabilities to access all social services including education. More appropriately, the concept has a broader meaning that includes all categories of people considered vulnerable and having difficulties or disadvantage accessing education. In the Zambian situation, inclusive education must go beyond only learners with disabilities to include vulnerable children such as those from very poor families whose self-esteem maybe affected as a result, girls who become pregnant and are re-enrolled to complete their education, 
refugees or children of refugees who are discriminated against on the basis of their nationality, children from minority languages groups, drop-outs who get back to school, HIV/AIDs orphaned children and other such disadvantaged persons.

First, the benchmarks for inclusion according to the United Nations (UN) Convention on Rights of Persons with Disabilities are equality of opportunity, non-discrimination, respect for differences and acceptance of the disabled as diversity, full and effective participation, accessibility, equality between men and women, respect for inherent dignity and autonomy to make choices; and respect for evolving capacities and identities of the disabled (Leonard Cheshire, 2019; Wonani \& Muzata, 2019). From our analysis, it appears like Zambia is far from the benchmarks although the country has a policy in place. This study establishes that while physical accessibility may be provided through the placement of the children with disabilities in inclusive classroom, in reality, children with disabilities do not derive practical benefit from their inclusion. Our study accords with the study by Ministry of Community Development (2018) showing, among other challenges such as lack of specialised materials and individual support, that many Zambian teachers lack skills to teach learners with disabilities in inclusive classrooms. The challenge of lack of skills among teachers and specialised materials is also confirmed by Simui, Muzata \& Mtonga (2019) who argue that learners with disabilities exist in schools but do not receive the services required because teachers are not trained to teach such learners and because materials are not available in accessible formats especially for learners with visual and hearing impairments. Accessibility, which is one of the key principles of inclusive education according to the UNCRPD, is broader than physical presence in the classroom. Learners should be seen to fully participate in the teaching and learning process within a classroom that is well resourced with accessible teaching and learning materials and blessed with teachers trained in inclusive methodologies.

While we recognise and commend the effort by the Ministry of General Education of Zambia for having put in place a policy on inclusion of learners with disabilities, the policy needs active support. It bears repeating that inclusive education should not be limited to learners with mild and moderate disabilities and should be a broader concept to drive education in Zambia so that it includes all categories of children that are vulnerable within the school system, and it should support their participation in learning. Thus, this calls for serious screening and assessment for disabilities and the inclusion of other vulnerable learners like children from poor families, pregnant girls, orphans, refuges and others to make inclusion real. Zambia needs to do this if we are to attain the Sustainable Development Goal number 4 on 
inclusion, equity and lifelong learning. The government should embrace at all costs the need to invest in technologies that help inclusion to be real if Zambia is to move forward with the inclusive education agenda. Currently, studies on inclusive education in Zambia show that learners have no access to computers and other ICTs that facilitate access to the curriculum (Simui, Kasonde-Ngandu and Nyaruwata, 2017; \& Mtonga, 2013). ICTs increase participation in learning and access to the curriculum. "Participation means that all learners are engaged in learning activities that are meaningful for them" (Mugambi, 2017:96). For instance, some ICTs such as Job Access to Windows (JAWs) have been known to allow learners with visual impairments have access to text materials for themselves instead of depending on someone read to them.

The study results showing lack of skills in teachers to teach learners with visual and hearing impairments in Zambian schools are not novel findings. It is clear that teachers who do not know how to read braille cannot help learners with visual impairments. Likewise, those who do know sign language cannot help those with hearing impairments. Muzata, (2018) argued that this problem starts from teacher training, while Johnson and Muzata (2019) propose a Universal Design for Learning to make inclusion real. There is a need for all stakeholders to be pro-active in the implementation of inclusive education.

The 2013 Curriculum Framework makes it clear that all teacher training colleges have a responsibility to train teachers in braille and sign language. However, the continued complaints of teachers not being skilled to teach in inclusive classrooms since 2014 when the revised curriculum started to be implemented leave a lot to be desired. In any case, even teachers that were already trained should already have had their capacity built or be retrained if really Zambia feels the need to effectively implement inclusive education. If the problem is in negative attitudes of officials found at the grassroots such as teachers, lecturers and their institutional administrators, then it is prudent as one of the participants mentioned (see, Teacher 104 excerpt), to institute frequent inclusive education implementation audits by the Education Standards Directorate. Inclusive education should not be merely paper based. It should be seen to work.

Challenges to policy implementation are normal but basic and obvious requirements like teacher skills for inclusive pedagogy should be provided. We are thus arguing that the failure to see practical inclusion effectively take place goes beyond a lack of resources. Rather, the lack of inclusive education methodologies curriculum in teacher education institutions, coupled with negative attitudes among teachers and other stakeholders in education are 
contributing factors. This study shows that the identified challenges are practical and addressable. We are of the opinion that Zambia's Ministry of General Education would find that most of the challenges identified in this study can be addressed if it intensifies teacher training in inclusive education. For instance, well-trained teachers can be reflective practitioners who also address negative attitudes, the lack of attention challenges, and stigmatisation and segregation from other learners. They are also able to better tackle unmodified curriculum, learner inferiority and other challenges based on their expertise that this study unveiled. While we recognise the need for specialised materials, an aspect of implementation of inclusive education besides teacher training that the Ministry of General Education should focus on is teacher training in inclusive pedagogies as a critical starting point to address many other challenges that inclusion is facing in the country's education system. So far, the Government of Republic of Zambia's policy on inclusive infrastructure has already started yielding fruits where, commendably, all new schools are required to be built with Universal Design Specificities to enable the inclusion of learners with disabilities.

There is further need to modify already existing structures such as classrooms, libraries and other buildings to make them more accessible to learners with disabilities. As one of the research participants mentioned, rural areas are the worse affected areas in terms of the poor implementation of inclusive education. But education should be seen as a right that requires not be negotiated for and so is inclusive education. All learners in all different schools merit access to the provision of equitable and quality education. But this can only be achieved when we understand inclusive education as a responsibility for all of us. Borrowing the words of Mugambi;

Inclusive education is thus a systematic change at all levels; principals, teachers, learners, school communities, policy makers, decision makers, families, and society at large. Access to mainstream education alone is not enough (Mugambi, 2017: 96).

Thus, all stakeholders have a stake in the implementation of inclusive education. Negative attitudes if not taken note of will negatively affect the implementation of inclusive education at all levels. We observe that the success of inclusive education lies in all stakeholders addressing many relevant factors but particularly stress the need for well-trained teachers in inclusive education and its methodologies. Ignoring the teacher leads to a continued cycle of challenges that appear again and again as though no attempt has ever been made to address such challenges. 


\section{Conclusion and Recommendations}

The study established that inclusive education being implemented in Zambian has so far focused largely on learners with mild and moderate disabilities. These learners are placed within the mainstream classrooms without support because teachers either lack skills for teaching learners with disabilities or have negative attitudes towards such learners. The lack of resources to support the teaching of learners with disabilities included in the mainstream classrooms exacerbates their disadvantages in the classroom because they do not benefit at all.

We therefore recommended that;

i. The Ministry of General Education should train both pre-service and in-service teachers in inclusive pedagogies for them to meet the learning needs of learners with disabilities in inclusive classrooms in Zambia.

ii. Since the concept of inclusion appears to be restricted to mild disability, the Ministry of General Education should scale-up the construction of the concept of inclusion so that it benefits other vulnerable groups in the Zambian society.

iii. To achieve meaningful inclusion, the Ministry of General Education in Zambia needs to address the high pupil-teacher ratio so that learners with disabilities included in the mainstream classroom can receive meaningful attention from teachers.

iv. An upscale of periodic inclusive education audit would be beneficial to help account for how inclusion is being implemented in Zambia.

v. We recommend better screening and assessment of disabilities to help identify other learners in need of inclusive education services in schools.

\section{References}

Al-Shammari, Zaid, Faulkner, Paula E., and Forlin, Chris. (2019). Theories based Inclusive Education Practices. In: Education Quarterly Reviews, 2 (2), 408-414. doi: 10.31014/aior.1993.02.02.73

Anastasiou, D. \& Kauffman. J.M. (2013). The Social Model of Disability: Dichotomy between Impairment and Disability. Journal of Medicine and Philosophy, 38: 441459. doi:10.1093/jmp/jht026.

Banja, M.K. \& Mandyata, (2018). Teachers' situational analysis of the integration of pupils with disability in selected primary schools in Zambia. Multidisciplinary Journal of Language and Social Sciences Education, 1 (1), 175-205. 
Chitiyo, M., \& Muwana, F. (2018). Positive Developments in Special Education in Zambia and Zimbabwe. International Journal of Whole Schooling. 14, (1).

Johnson, E. \& Muzata, K.K. (2019). 'Inclusive Education: Implementing Universal Design for Learning'. In: M.K. Banja (ed.). Selected Readings in Education vol 2 (pp. 1-22), Lusaka: Marvel Publishers.

GRZ, (2012). The Persons with Disability Act 2012 No 6, of 2012 67.Available @ http://www.parliament.gov.zm/sites/default/files/documents/acts/The\%20Persons\%20 with\%20disabilities\%20act\%2C\%202012.PDF.

Kasongole, G. \&Muzata, K.K. (2020). Inclusive Education for Learners with Learning Disabilities in Two Selected Primary Schools of Kabwe-Zambia: A Myth or Reality. International Journal of Humanities Social Sciences and Education (IJHSSE), 7 (1), $1-16$.

Leonard Cheshire, (2019). The Disability Rights Advocacy and Campaign Project. Leonard Cheshire.

Leonard Cheshire, (2019). Understanding Disability: A training manual for communities on the convention on the rights of Persons with Disabilities. Leonard Cheshire.

MESVTEE, (2013). Zambia: Education Curriculum Framework 2013. Lusaka: Curriculum Development Centre.

Ministry of Community Development and Social Services, (2018). Disability And Education: Qualitative study from Zambia on barriers to and facilitators of life-long learning, National Disability Survey Report.

Ministry of Education, (1996). Education our Future. Lusaka: Zambia publishing house.

Ministry of General Education, (2016). Inclusive education and special education in Zambia: Implementation Guidelines: Lusaka: Ministry of General Education.

MoE. (2014). Principles \& practice: Teaching the deaf in schools; Teachers' guide. Lusaka: Missionary Oblates Printing Press.

Mtonga, T, (2013). A Situational Analysis on the Availability and Access to Computers for Educational Purposes by Learners with Visual Impairments in Zambia: A Case of Three Basic and Three High Schools'. IEEE. 
Mugambi, M.M. (2017). Approaches to Inclusive Education and Implications for Curriculum Theory and Practice. International Journal of Humanities Social Sciences and Education (IJHSSE) 4 (10), 92-106, http://dx.doi.org/10.20431/23490381.0410013.

Mulonda, M. (2013). A situational analysis on the use of sign language in the education of the deaf in Zambia: a case of Magwero and St Josephs for the deaf. Masters' thesis: University of Zambia.

Mumba, P. (2000). Democratisation of Primary Classrooms in Zambia: A case study of its implementation in a rural primary school in Mpika in M. Ainscow and P. Mittler (Eds) Including the Excluded. Proceedings of $5^{\text {th }}$ International Special Education Congress, University of Manchester. Delph: Inclusive Technology Ltd.

Mumba, P. (2001). Democratisation of the classroom. In Enabling Education, Issue 5, p.5. Manchester: EENET. www.eenet.org.uk/newsletters/news5/p5.shtml (accessed July 21 2008)

Muwana, F. (2012). Zambian student teachers' attitudes toward including students with disabilities in general education classrooms. Doctoral dissertation: University of Illinos.

Muwana, F. C. (2012). Zambian Student Teachers' Attitudes towards Including Students with Disabilities In General Education Classrooms, (Unpublished Masters dissertation, University of Illinois).

Muzata, K.K. \&Mahlo, D. (2019).Teachers' Knowledge of curriculum adaptation and adaptation strategies for learners with special educational needs in Zambia. Journal of New Vision in Educational Research, 1 (1), 17-35.

Muzata, K.K. (2018). Teaching Skills of Special Education Students during Teaching Practice: The Case of the University of Zambia Pre-service Special Education Students. Multidisciplinary Journal of language and Social Sciences Education, 1, (1), 103-137.

Muzata, KK, Simalalo, M., Kasonde-Ng'andu, S., Mahlo,D., Banja, MK \&Mtonga, T. (2019). Perceptions of Students with Visual Impairments towards their Inclusion in the Faculty of Education at the University of Zambia: A Phenomenological study: Multidisciplinary Journal of Language and Social Sciences Education, 2 (2) 170 210.

Ndonyo, T.M. (2007). Teacher perceptions of inclusive education: Case of Solwezi District Basic Schools. Masters dissertation- University of Zambia. Available @ http://dspace.unza.zm:8080/xmlui/handle/123456789/2066. 
Paju, B., Kajamaa, A., Pirttimaa, R \&Kontu, E.(2018).Contradictions as Drivers for Improving Inclusion in Teaching Pupils with Special Educational Needs. Journal of Education and Learning; 7 (3), 11-22.

Retief, M. \& Letšosa, R. (2018). Models of disability: A brief overview. HTS Teologiese Studies/Theological Studies. 74(1), a4738. https://doi.org/10.4102/hts.v74i1.4738.

Simui, F. (2018). Lived Experiences of Students with Visual Impairments at Sim University in Zambia: A Hermeneutic Phenomenological Approach. Unpublished $\mathrm{PhD}$ thesis, University of Zambia, Lusaka. http://dspace.unza.zm/handle/123456789/5884

Simui, F., Kasonde-Ngandu, S. \& Nyaruwata, L.T. (2017). ICT as an enabler to academic success of Students with Visually Impaired at Sim University: Hermeneutics approach. Zambia ICT Journal, 1(1), 59. https://doi.org/10.33260/zictjournal.v1i1.9

Simui, F., Kasonde-Ngandu, S., Cheyeka, A.M. \& Makoe, M. (2019). Lived Disablers to Academic Success of the Visually Impaired at the University of Zambia, Sub-Saharan Africa. Journal of Student Affairs in Africa, 7(2), 41-56. DOI: 10.24085/jsaa.v7i2.3824

Simui, F., Muzata, K.K \& Mtonga, T. (2019). A report on the Status of Education in Zambia: Focus on Inclusiveness of Learners with Special Education Needs submitted to the Zambia National Coalition: Lusaka: ZANEC.

United Nations, (1948). Universal Declaration of Human Rights.

United Nations, (1989). Convention on the Rights of Persons with Disability.

United Nations, (2006). Convention on the Rights of Persons with Disabilities (CRPD).

Wonani. L. \& Muzata, K.K. (2019). Parenting and Educating Children with Autism: Lived Experiences of Lusaka Parents - Zambia. International Journal of Sciences: Basic and Applied Research (IJSBAR), 48, (6), 20 -36. 